\title{
Editorial - Ten Trends Shaping the Future of Marketing: Considerations for the Academics
}

\author{
Hiram Ting \\ Faculty of Hospitality and Tourism Management, UCSI University, Malaysia
}

\section{Kim-Shyan Fam}

Victoria University of Wellington, Wellington, New Zealand

\section{Yoong-Wai Chan}

Faculty of Accountancy, Finance, and Business, Tunku Abdul Rahman University College, Kuala Lumpur, Malaysia

\section{Jun-Hwa Cheah}

Faculty of Economics and Management, Universiti Putra Malaysia, Selangor, Malaysia

\begin{abstract}
This Editorial provides a bird's-eye view of ten current marketing trends based on business magazines available online and reviews articles published in top marketing journals. Its intent is to highlight the need for academics and researchers to observe the real world and learn about the pertinent issues in the industry and the community. We found that authors or researchers who published in top journals are acquainted to societal issues and development. While the rigor of research in the theoretical and methodological aspects is unequivocally upheld, the relevance of the study to the populations concerned is evident. As such industrial learning and engagement as well as the convergence of knowledge and resources between academia and industry will likely enhance the academics' idea generation, problem formulation and ultimately the impact validity of their publications.
\end{abstract}

Keywords: Publication, Impact Validity, Marketing Trends, Industry Engagement 


\section{Background}

Academics at the tertiary level are historically seen as the public intellectuals; therefore they are entrusted with the roles of building knowledge and disseminating it to the society (Bender, 1997). One of their primary obligations is to carry out research that provides insights into the phenomenon of interest and informs action and addresses societal needs. Nevertheless, as academia is becoming more corporatized in recent years, such as the pursuit of status in national and global ranking of universities, the institutional missions and personal motivations begin to change (Granek \& Nakash, 2016). Expectations to bring in as much money as possible to the university through grants or projects and to publish as much research as possible in indexed journals through conference presentation or regular submission to achieve performance targets are prevailing (Riggs, 2013). As a result, many social science studies and the subsequent publications are found lacking of practical relevance or meaningfulness to the populations. While universities and academics should continue to focus on research projects and publications, many of these works appear to be void of real impact to the society. One of the concerns could be due to the fact that many academics are short of industrial experience or have no or limited engagement with the populations concerned.

Hence a few questions arise. Should academics be more involved in industrial work in order to better understand the phenomenon under investigation? Should the researchers learn something from the practitioners and conduct research accordingly to not only make theoretical contribution but also substantial impact on the real world? By "real world," we mean people outside of laboratory or academic conference that refer to the actual situations out there. In articulating the magnitude of having a positive impact on the real world, the phrase "impact validity" is introduced (Massey \& Barreras, 2013) and requires further consideration. Unlike other validity estimates, impact validity is about the extent to which research outcomes translate into something practical and bring positive effect to the public in actuality. Such an impact should be more than simply the production of data through statistical software and techniques, such as reporting and interpretation of p-value to determine certain relationships (Baker, 2016; Wasserstein \& Lazar, 2016). The bottom line is that our research should be of use to the real world or the populations that we study (Granek \& Nakash, 2016).

Instead of looking at social sciences in general, we will discuss about marketing specifically in this Editorial. We will explicate ten trends which are happening now and will likely shape the future of marketing with reference to some of the well established business magazines available online, such as Forbes (https://www.forbes.com/) and Harvard Business Review (https://hbr.org/), followed by some recommendations based on the review of recent literature published in top marketing journals, such as Journal of the Academic Marketing Science, Journal of interactive, Journal of Marketing Research, Journal of Retailing, Journal of Advertising and European Journal of Marketing. It is not our intent to provide an exhaustive list of marketing trends nor an extensive review of recent marketing literature in this Editorial; instead we would like to use them as a basis to encourage marketing academics and researchers, including the emerging ones and students, to consider solemnly not only about what topic we do but also how we translate that 
knowledge into something useful to our respective worlds in our current or next research projects.

\section{Ten Marketing Trends}

We spent some weeks reading online news and articles about marketing strategies and practices in different parts of the world. Though we did not employ a full scale qualitative study, we evaluated what we read and concluded our discussion with ten marketing trends in the contemporary society. Note that these trends are by no means exhaustive and their importance differ by countries and organizations. Nevertheless these trends should provide some ideas to marketing academics and the young researchers about the future of marketing.

\section{Brands loyalty with authentic storytelling}

Modern consumers are becoming more self-directed. They are looking for content which is more appealing - it does more than just a customary promotion. Hence, they are seeking for personalized experience in the communication process. Despite running a small business or starting a new business, designing a campaign that tells an authentic story across multiple channels, connecting with people in real-time, is found to be critically vital in the contemporary setting.

\section{The effectiveness of digital display ads}

Notwithstanding the rise of ad-blocking software, business practitioners have been increasingly investing in social and mobile ads by adopting the hyper-personalized content and experience from augmented reality (AR) to live content across multiple platforms. With numerous intricate touch points and a decision journey for customers whose needs and demands are changing from time to time, tapping onto the above is believed to be an ingredient for business success.

\section{The role of influencer marketing}

Influencer marketing is a classic social media marketing strategy which is growing rapidly in today digital era. Organizations previously relied on celebrity endorsement to convince people that their products are worth buying. Today, however, consumers are more inclined to checking what their peers do as to avoid missing out. Moreover, they could relate themselves better to individuals who share similar interest or are in the same social groups. People are putting more trust in others they know or can relate to instead of ads.

\section{The role of $\mathrm{AI}$ in integrating chatbots and automation to enhance campaign optimization}

Organizations and consumers have begun to notice artificial intelligence (AI) and realize its impact on their respective activities and the society at large. Some businesses have begun using AI in ad exchanges and for campaign optimization. In order to remain competitive and relevant in the market, it is imperative to explore and 
execute effective ways to integrate AI into consumer experience with chatbots and automation in order to supplement customer engagement, satisfaction and loyalty.

\section{The practice of better data hygiene in the big data era}

Most businesses are overwhelmed by loads of unstructured information which comes in different shapes and sizes. Data is king and any prudent marketers recognize the huge potential in big data. However, it is inadequate to only gather or compile data. With robust data signals, marketers can turn data into intelligence and utilise relevant insights to develop smarter and better-targeted marketing activities. The challenge is therefore on how to discern and extract the useful insights from the noisy data waste.

\section{The prevalence of personalization in product design and communication in the context of big data}

In light of the aforementioned, we come to the sixth trend. Given the co-existence of big data, flexible manufacturing, and social media, organizations are learning to offer customized products and designs to their target consumers. For example, some pharmaceutical companies have moved into personalized medication service based on the differences of patients, such as their age, gender, weight, and medical history. Such customization or diversification of service was seemed impossible and impractical in the past when most activities were done manually.

\section{Adoption of AI in different settings and consumer behaviour scenario}

AI is redefining various industries by providing greater personalization to users, automating processes, and even disrupting the manner organizations and consumers work for a long time. For example, some travel companies have long seen the value in leveraging on chatbots to create ever-present, personalized concierge level service at scale. Moreover, AI facilitates healthcare professionals to examine diseases, detect high-risk patient groups, automate diagnostic tests and enhance the speed and accuracy of treatment which in turn can positively impact the quality of healthcare and subsequently human lives or well-being.

\section{The integration of video into consumer journey}

Since video marketing is highly visual and auditory, it is easier for consumers to remember and retain what they see than that of text-based content. When consumers are exposed to so much information every day, seeing the video marketing content will likely enable them to remember the brand, which translates to more sales. Evidently, consumers usually like to share videos they enjoy in social media which can naturally expand the online reach. It goes without saying that designing an effective video that captures consumers' attention and interest is essential.

\section{The integration of machine learning into marketing automation}

Machine learning takes the contextual content, marketing automation including crosschannel marketing campaigns and lead scoring, personalization, and sales forecasting to a new level of accuracy and speed. Machine learning is adopted by marketers to understand, anticipate, and act on the problems their sales prospects are trying to 
solve faster and with more clarity than any competitor. By having the insight to tailor content while qualifying leads for sales to close quickly is being fuelled by machine learning-based apps capable of learning what is the most effective for each prospect and customer.

\section{Big data studies using meta-analysis, systematic literature review or narrative review}

In marketing, big data is providing insights into which content is the most effective at each stage of a sales cycle, how investments in Customer Relationship Management (CRM) systems can be improved, in addition to strategies for increasing conversion rates, prospect engagement, revenue, and customer lifetime value. With big data, it is possible for leading marketers to deliver consistent omni-channel customer experiences across all channels. Therefore, it is crucial to understand the general taxonomy of big data and its role in capturing business value through analysing the definitional perspectives.

\section{Brief Review of Recent Marketing Literature}

When reviewing recent articles published in top marketing journals, it is evident that these authors are well connected to the contemporary phenomena and are endeavouring to provide greater insights while maintaining the rigor of research in theoretical and methodological aspects. For example, recent studies have been looking into how new marketing technologies change consumer decision-making, information process and various behavioural aspects (Hilken, de Ruyter, Chylinski, Mahr \& Keeling, 2017; Steinhoff, Arli, Weaven \& Kozlenkova, 2019). Specifically some of these studies delve into the effect of multisensory technologies, such as virtual reality, augmented reality, and various sensory inputs (including offline reality) on consumer's perception and behaviour in digital environments (Biswas, Lund \& Szocs, 2019; Helmefalk, 2019; Motoki, Saito, Nouchi, Kawashima \& Sugiura, 2019; Petit, Velasco \& Spence, 2019; Rauschnabel, Felix \& Hinsch, 2019).

Recent studies also investigate subjects related to personalization and customization, such as the use of mobile applications and various communication tactics to enhance business performance and facilitate consumer's decisions and experience (Cheah, Ting, Cham \& Memon, 2019; Steinhoff et al. 2019). Personalization is effective in the current environment as organizations have access to large volume of data on customer's purchase behaviour, website browsing, and preferences that can be analysed to create customer profiles (Liu-Thompkins, 2019; Schreiner, Rese \& Baier, 2019; Shanahan, Tran \& Taylor, 2019; Strycharz, van Noort, Helberger \& Smit, 2019). Similarly, omni-channeling or multi-channel integration is increasingly being investigated to manage consumers' expectations and explain behavioural outcomes, such as purchase intention, loyalty and satisfaction (Akter, Hossain, Lu, Aditya, Hossain \& Kattiyapornpong, 2019; Herhausen, Binder, Schoegel \& Herrmann, 2015; Huré, Picot-Coupey \& Ackermann, 2017; Lee, Chan, Chong \& Thadani, 2018; Shareef, Dwivedi \& Kumar, 2016; Shen, Li, Sun \& Wang, 2018; Verhoef, Kannan, \& Inman, 2015; Yurova, Rippé, Weisfeld-Spolter, Sussan \& Arndt, 2017). 
Given the complexity of the contemporary setting, other major issues, such as service experience and customer's response on service delivery (Van Vaerenbergh, Varga, De Keyser \& Orsingher, 2018; Wan \& Wyer, 2018) as well as green branding and green marketing (Papista \& Dimitriadis, 2019; Wu, Wei, Tseng \& Cheng, 2018) require continual investigation. Having said that, specific topics such as pop-up retail (Lunardo \& Mouangue, 2019; Spitzkat \& Fuentes, 2019), shopping cart abandonment (Huang, Korfiatis \& Chang, 2018), selling cues (Das, Mukherjee \& Smith, 2018; Yu, Hudders \& Cauberghe, 2018), ambient scents (Girard, Lichters, Sarstedt \& Biswas, 2019) as well as the use of chatbots and robots in marketing activities (Chung, Ko, Joung \& Kim, 2018; Kim, Schmitt \& Thalmann, 2019; Murphy, Gretzel \& Pesonen, 2019; Mende, Scott, van Doorn, Grewal \& Shanks, 2019) are as important because these are what organizations and customers are experiencing today.

\section{Recommendations}

We attempt to provide a bird's-eye view of the current marketing trends in the real world and a brief review of what is written and published in top marketing journals in recent years. Note-worthily, these two "worlds" (industry and academia) actually agree on most of the contemporary issues and topics. Suffice it to say these authors not only possess advanced marketing knowledge, but also practical understanding of what is happening and how things are developing overtime and in the foreseeable future. As such we would like to recommend marketing academics, researchers and students to be more active in equipping themselves with industrial experience. If students are required to go for internship as part of their learning process, academics should go through similar exercise in order to observe and learn what is happening out there. There are plenty of rooms for academics and practitioners to work together and the convergence of knowledge and resources will surely bring about a greater impact to the real world. Industrial engagement, be it imposed or encouraged, be it done voluntarily or arranged purposefully, would enhance their idea generation, problem formulation and subsequently impact validity of their publications.

The ability to write papers which are theoretically sound, methodologically rigorous and practically meaningful with good stories (related to the issues) will likely give academics or researchers the edge to publish in top marketing journals. It is something we should learn today, rather than avoid, neglect or ignore. Although the scope of what reality can be and how it looks like in practice can be challenging to grasp for academics at times, it leaves an open space for seeing more than what was previously seen, and designing something better and more purposeful (hence more meaningful findings) to the populations concerned (Granek \& Nakash, 2016; Lavis, 2006; Woolf, 2008). With that, we will like to end our Editorial with a passage taken from a recent paper by Professor Robert Palmatier published in Journal of Academy of Marketing Science:

"Successful marketing strategy researchers recognize that sales and marketing managers are the key stakeholders and consumers of their papers' insights and implications. However, insights can flow both ways. As a strategy researcher, editor, and past AE at JM, I feel that the benefits of closely collaborating with businesses to develop and execute academic research are often underestimated. Rapid changes in technology, globalization, legislation and big data are evoking vast shifts in sales and 
marketing activities and strategies at an accelerating rate, and firms often face business issues that the academic community has not yet addressed - or even recognized in some cases. In my experience, researchers who work closely with firms, perhaps through affiliations with research centres, are also working on the most interesting, emerging topics, with excellent access to data that enable them to address their research questions convincingly (e.g., longitudinal consumer data, randomized field or natural experiments). Focusing on current business problems with good data often results in high impact papers that are eligible for awards, citations, and references in business press. Accordingly, my recommendations to strategy researchers are to help build a research centre at the university or become affiliated with one of the many existing research centres to connect with today's firms and the issues they confront" (Palmatier, 2018, p. 986).

\section{References}

Akter, S., Hossain, M. I., Lu, S., Aditya, S., Hossain, T. M. T., \& Kattiyapornpong, U., (2019), Does service quality perception in omnichannel retailing matter? A systematic review and agenda for future research, in Exploring Omnichannel Retailing, pp. 7197.

Baker, M., (2016), Statisticians issue warning over misuse of $\mathrm{P}$ values, Nature News, vol. 531, no. 7593 , p. 151.

Bender, T., (1997), Intellect and public life: Essays on the social history of academic intellectuals in the United States, Baltimore: Johns Hopkins University Press.

Biswas, D., Lund, K., \& Szocs, C., (2019), Sounds like a healthy retail atmospheric strategy: Effects of ambient music and background noise on food sales, Journal of the Academy of Marketing Science, vol. 47, no. 1, pp. 37-55.

Cheah, J. H., Ting, H., Cham, T. H., \& Memon, M. A., (2019), The effect of selfie promotion and celebrity endorsed advertisement on decision-making processes: A model comparison. Internet Research, Forthcoming.

Chung, M., Ko, E., Joung, H., \& Kim, S. J., (2018), Chatbot e-service and customer satisfaction regarding luxury brands, Journal of Business Research, forthcoming.

Das, G., Mukherjee, A., \& Smith, R. J., (2018), The perfect fit: The moderating role of selling cues on hedonic and utilitarian product types, Journal of Retailing, vol. 94, no. 2, pp. 203-216.

Girard, A., Lichters, M., Sarstedt, M., \& Biswas, D., (2019), Short- and long-term effects of nonconsciously processed ambient scents in a servicescape: Findings from two field experiments, Journal of Service Research, forthcoming.

Granek, L., \& Nakash, O., (2016), The impact of qualitative research on the "real world" knowledge translation as education, policy, clinical training, and clinical practice, Journal of Humanistic Psychology, vol. 56, no. 4, pp. 414-435.

Helmefalk, M., (2019), Browsing behaviour as a mediator: The impact of multi-sensory cues on purchasing, Journal of Consumer Marketing, vol. 36, no. 2, pp. 253-263.

Herhausen, D., Binder, J., Schoegel, M., \& Herrmann, A., (2015), Integrating bricks with clicks: retailer-level and channel-level outcomes of online-offline channel integration, Journal of Retailing, vol. 91, no. 2, pp. 309-325.

Hilken, T., de Ruyter, K., Chylinski, M., Mahr, D., \& Keeling, D. I., (2017), Augmenting the eye of the beholder: Exploring the strategic potential of augmented reality to enhance online service experiences, Journal of the Academy of Marketing Science, vol. 45, no. 6, pp. 884-905.

Huang, G. H., Korfiatis, N., \& Chang, C. T., (2018), Mobile shopping cart abandonment: The roles of conflicts, ambivalence, and hesitation, Journal of Business Research, vol. 85, pp. 165-174. 
Huré, E., Picot-Coupey, K., \& Ackermann, C. L., (2017), Understanding omni-channel shopping value: A mixed-method study, Journal of Retailing and Consumer Services, vol. 39, pp. 314-330.

Kim, S. Y., Schmitt, B. H., \& Thalmann, N. M., (2019), Eliza in the uncanny valley: Anthropomorphizing consumer robots increases their perceived warmth but decreases liking, Marketing Letters, vol. 30, no. 1, pp. 1-12.

Lavis, J., (2006), Research, public policymaking, and knowledge-translation processes: Canadian efforts to build bridges, Journal of Continuing Education in the Health Professions, vol. 26, no. 1, pp. 37-45.

Lee, Z. W., Chan, T. K., Chong, A. Y. L., \& Thadani, D. R., (2019), Customer engagement through omnichannel retailing: The effects of channel integration quality, Industrial Marketing Management, vol. 77, pp. 90-101.

Liu-Thompkins, Y., (2019), A decade of online advertising research: What we learned and what we need to know, Journal of Advertising, forthcoming.

Lunardo, R., \& Mouangue, E., (2019), Getting over discomfort in luxury brand stores: How pop-up stores affect perceptions of luxury, embarrassment, and store evaluations, Journal of Retailing and Consumer Services, vol. 49, pp. 77-85.

Massey, S. G., \& Barreras, R. E., (2013), Introducing "impact validity", Journal of Social Issues, vol. 69, no. 4, pp. 615-632.

Mende, M., Scott, M. L., van Doorn, J., Grewal, D., \& Shanks, I., (2019), Service robots rising: How humanoid robots influence service experiences and elicit compensatory consumer responses, Journal of Marketing Research, forthcoming.

Motoki, K., Saito, T., Nouchi, R., Kawashima, R., \& Sugiura, M., (2019), Light colors and comfortable warmth: Crossmodal correspondences between thermal sensations and color lightness influence consumer behavior, Food Quality and Preference, vol. 72, pp. 45-55.

Murphy, J., Gretzel, U., \& Pesonen, J., (2019), Marketing robot services in hospitality and tourism: the role of anthropomorphism, Journal of Travel \& Tourism Marketing, forthcoming.

Palmatier, R. W., (2018), Advancing marketing strategy research, Journal of the Academy of Marketing Science, vol. 46, pp. 983-986.

Papista, E., \& Dimitriadis, S., (2019), Consumer-green brand relationships: Revisiting benefits, relationship quality and outcomes, Journal of Product \& Brand Management, vol. 28, no. 2, pp. 166-187.

Petit, O., Velasco, C., \& Spence, C., (2019), Digital sensory marketing: Integrating new technologies into multisensory online experience, Journal of Interactive Marketing, vol. 45 , pp. 42-61.

Rauschnabel, P. A., Felix, R., \& Hinsch, C., (2019), Augmented reality marketing: How mobile AR-apps can improve brands through inspiration, Journal of Retailing and Consumer Services, vol. 49, pp. 43-53.

Riggs, D. W., (2013), Impact validity: A politics of possibilities, Journal of Social Issues, vol. 69, no. 4, pp. 797-803.

Schreiner, T., Rese, A., \& Baier, D., (2019), Multichannel personalization: Identifying consumer preferences for product recommendations in advertisements across different media channels, Journal of Retailing and Consumer Services, vol. 48, pp. 87-99.

Shanahan, T., Tran, T. P., \& Taylor, E. C., (2019), Getting to know you: Social media personalization as a means of enhancing brand loyalty and perceived quality, Journal of Retailing and Consumer Services, vol. 47, pp. 57-65.

Shareef, M. A., Dwivedi, Y. K., \& Kumar, V., (2016), Exploring multichannel design: Strategy and consumer behaviour, The Marketing Review, vol. 16, no. 3, pp. 235-263.

Shen, X. L., Li, Y. J., Sun, Y., \& Wang, N., (2018), Channel integration quality, perceived fluency and omnichannel service usage: The moderating roles of internal and external usage experience. Decision Support Systems, vol. 109, pp. 61-73. 
Spitzkat, A., \& Fuentes, C., (2019), Here today, gone tomorrow: The organization of temporary retailscapes and the creation of frenzy shopping, Journal of Retailing and Consumer Services, vol. 49, pp. 198-207.

Steinhoff, L., Arli, D., Weaven, S., \& Kozlenkova, I. V., (2019), Online relationship marketing, Journal of the Academy of Marketing Science, vol. 47, no. 3, pp. 1-25.

Strycharz, J., van Noort, G., Helberger, N., \& Smit, E., (2019), Contrasting perspectivespractitioner's viewpoint on personalised marketing communication, European Journal of Marketing, vol. 53, no. 4, pp. 635-660.

Van Vaerenbergh, Y., Varga, D., De Keyser, A., \& Orsingher, C., (2018), The service recovery journey: Conceptualization, integration, and directions for future research, Journal of Service Research, vol. 22, no. 2, pp. 103-119.

Verhoef, P. C., Kannan, P. K., \& Inman, J. J., (2015), From multi-channel retailing to omnichannel retailing: Introduction to the special issue on multi-channel retailing, Journal of Retailing, vol. 91, no. 2, pp. 174-181.

Wan, L. C., \& Wyer Jr, R. S., (2018), The influence of incidental similarity on observers' causal attributions and reactions to a service failure, Journal of Consumer Research, vol. 45, no. 6, pp. 1350-1368.

Wasserstein, R. L., \& Lazar, N. A., (2016), The ASA's statement on p-values: Context, process, and purpose, The American Statistician, vol. 70, no. 2, pp. 129-133.

Woolf, S. H., (2008), The meaning of translational research and why it matters, Journal of the American Medical Association, vol. 299, no. 2, pp. 211-213.

Wu, H. C., Wei, C. F., Tseng, L. Y., \& Cheng, C. C., (2018), What drives green brand switching behavior?, Marketing Intelligence \& Planning, vol. 36, no. 6, pp. 694-708.

Yu, S., Hudders, L., \& Cauberghe, V., (2018), Are fashion consumers like schooling fish? The effectiveness of popularity cues in fashion e-commerce, Journal of Business Research, vol. 85, pp. 105-116.

Yurova, Y., Rippé, C. B., Weisfeld-Spolter, S., Sussan, F., \& Arndt, A., (2017), Not all adaptive selling to omni-consumers is influential: The moderating effect of product type, Journal of Retailing and Consumer Services, vol. 34, pp. 271-277. 